\title{
Electrical Impedance Tomography in Acute Respiratory Distress Syndrome
}

\author{
Inéz Frerichs", Sven Pulletz, Gunnar Elke, Günther Zick and Norbert Weiler
}

\author{
Department of Anaesthesiology and Intensive Care Medicine, University Medical Centre Schleswig-Holstein, Campus \\ Kiel, Kiel, Germany
}

\begin{abstract}
Electrical impedance tomography (EIT) is an emerging new imaging modality not yet routinely used in a clinical setting. The generation of EIT scans is based on the non-invasive measurement of electrical properties of tissues which does not require the use of radiation. Thoracic EIT examinations have been shown to track changes in regional lung volumes at scan rates of up to 40-50 scans/s. Experimental and clinical studies indicate the potential of EIT in monitoring regional lung ventilation and aeration at the bedside. Mechanically ventilated patients with acute lung injury and acute respiratory distress syndrome (ARDS) might benefit from possible continuous monitoring of their regional lung function by EIT which could be used to optimise the ventilator settings and minimise the ventilator-induced lung injury. This review explains the measuring principle of EIT and the analysis of regional EIT signals which allow the assessment of regional lung ventilation, aeration and potentially also lung perfusion. Protective lung ventilation using low tidal volumes and adequate positive end-expiratory pressures, recruitment manoeuvres, surfactant administration, prone posture, restricted fluid administration, assisted ventilation allowing spontaneous breathing, partial liquid ventilation, administration of pulmonary vasoactive, anti-inflammatory and antioxidant agents are used or considered in the management of ARDS patients. EIT is capable of monitoring the pulmonary effects of many of these therapeutic procedures. This is documented by examples from experimental and clinical EIT studies and by references to relevant EIT literature. The perspectives and limitations of EIT monitoring are also addressed.
\end{abstract}

Keywords: Electrical impedance tomography, EIT, lung ventilation, lung perfusion, monitoring, lung imaging.

\section{INTRODUCTION}

Adult respiratory distress syndrome (ARDS) as the most severe form of acute lung injury is a highly lethal syndrome. The pooled mortality from ARDS since 1994, when the clinical definition of this syndrome has been agreed on [1], has been found to be $44 \%$ in prospective observational studies and $36 \%$ in randomised controlled trials [2]. Although it is assumed that mortality from ARDS is decreasing [3-5], it is still very high and even the claimed fall in mortality has been recently questioned [2].

Thus, ARDS remains a challenging critical care illness and the optimum management of ARDS patients is still a matter of debate. Many of the used or proposed therapeutic procedures are supportive in nature and do not selectively target pathophysiologic processes in the early developmental stages of the syndrome. This is in part related to the fact that various pulmonary and non-pulmonary insults may elicit or contribute to the development of ARDS. All of these insults lead to a severe damage of the alveolarcapillary membrane with increased permeability. The accumulation of proteinrich fluid and activated cells (neutrophils and macrophages) disturb the synthesis and function of surfactant and initiate proinflammatory processes leading to the development of lung injury. The primary physiological function of the lungs,

*Address correspondence to this author at the Department of Anaesthesiology and Intensive Care Medicine, University Medical Centre Schleswig-Holstein, Campus Kiel, Schwanenweg 21, D-24105 Kiel, Germany; Tel: 0049/431/597-2991; Fax: 0049/431/597-3002;

E-mail: frerichs@anaesthesie.uni-kiel.de the gas exchange, is dramatically impaired and the patients require mechanical ventilation.

Due to severe hypoxemic respiratory failure, mechanical ventilation is a life-saving measure in ARDS patients. However, artificial ventilation as such is known to exhibit injurious effects on the lung tissue known as ventilator-induced lung injury. The selection of least injurious ventilator settings should be aspired in ARDS patients. However, this is difficult to accomplish on the background of the non-homogeneous distribution of lung injury, dramatically decreased lung compliance, increased pulmonary arterial pressures and ventilation/perfusion mismatch.

The crucial role of mechanical ventilation and the negative effects of improper ventilator settings on the outcome of ARDS patients have been clearly demonstrated by the deleterious effects of high tidal volumes [6]. The securing of lung protective ventilation is, along with the therapy of the underlying cause of ARDS, the only generally accepted standard measure in management of ARDS patients with a higher level of evidence. As stated above, the selection of the most adequate ventilator settings is challenging and should be continuously adapted to the instantaneous state of the regional lung function. This should ideally be achieved on the basis of feedback information provided by continuous monitoring of the regional lung function. This type of information is not available at the bedside at present. We believe that, in the future, electrical impedance tomography (EIT) might become this monitoring tool. 


\section{THE NEED FOR A NEW TYPE OF MONITORING}

Patients suffering from ARDS require an intensive care treatment and are continuously examined by numerous established medical monitoring methods. The critically compromised lung function and the adequacy of ventilator settings are monitored by, e.g., blood gas analysis, transcutaneous $\mathrm{O}_{2}$ saturation measurement and measurement of lung mechanics. These methods provide only global information without the ability to detect and locate regional inhomogeneities which are characteristic for ARDS. Imaging methods, chest radiography and computed tomography (CT), are also regularly used. They allow the visualisation of changes in lung morphology on a regional scale. The disadvantages of these methods are the increased radiation load and the necessity of patient transport from the intensive care unit to the CT examination site which is associated with an increased risk for the patient. Further drawback is the fact that both chest X-ray and $\mathrm{CT}$ examinations provide primarily information on the lung structure at the time of examination and can not directly assess the lung function continuously. Thanks to its non-invasive and radiation-free measuring principle and the possibility of bedside use EIT exhibits features which are superior to those of the classical imaging methods. Moreover, EIT is able to assess regional lung function during long time periods. Thus, EIT could become a new useful monitoring tool in addition to the already available methods.

\section{MEASURING PRINCIPLE AND BASIC CHARACTERISTICS OF EIT}

EIT generates cross-sectional images of the parts of human body, e.g., the chest, based on the measurement of electrical properties of biological tissues. These properties can be quantitatively characterised by electrical bioimpedance which is defined as the opposition of the tissues to the passage of alternating electrical current. Different tissues exhibit different values of electrical bioimpedance $[7,8]$. For instance, the lung tissue has higher impedance than the muscle. Electrical bioimpedance changes with the functional state of the tissue or organ, e.g., the lung impedance is higher during inspiration than during expiration. Moreover, pathological changes modify the electrical tissue properties, e.g., lung oedema decreases the pulmonary electrical impedance. This means that if regional electrical impedance of the lungs is assessed by EIT with a sufficient sampling rate over longer periods of time then both physiological and pathophysiological processes can be determined and followed.

An EIT examination requires an array of electrodes which, in the case of a thoracic examination, must be placed on the chest circumference (Fig. 1). Either single electrodes (e.g., ECG electrodes or other types of self-adhesive electrodes) or electrodes integrated into a belt are used. The electrodes are involved in two basic repetitive processes: 1 ) the application of very small alternating electrical currents which are in the range of only few $\mathrm{mA}$ and 2) the measurement of potential differences. Most of the EIT devices use a set of 16 electrodes, although systems with 8 or 32 electrodes have also been developed. The 16-electrode systems have a higher resolution than the 8-electrode systems. As an electrical contact between the electrodes must be avoided, this can easier be accomplished in the 16electrode devices than in those using a higher number of electrodes, especially when the chest circumference is small, as in children.

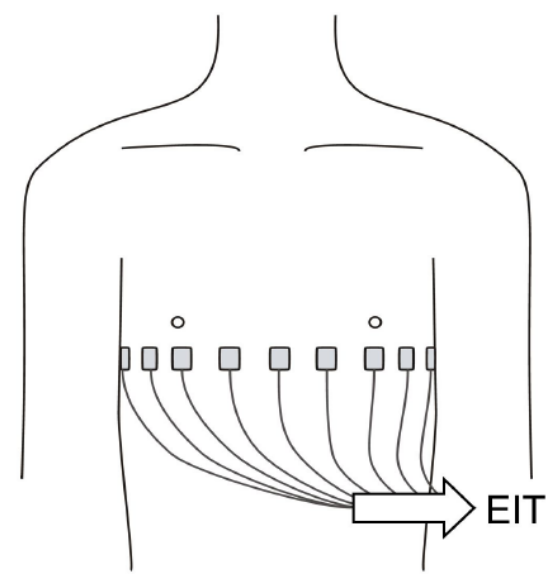

Fig. (1). Thoracic EIT examination. An array of surface electrodes is placed on the chest circumference and connected with the EIT device. Very small alternating electrical currents are sequentially applied between all pairs of adjacent electrode pairs. During each current injection the resulting electrical potential differences are measured between all passive electrode pairs. The sets of acquired voltages are used to calculate the distribution of electrical impedance within the chest.

During an EIT examination, cyclic injections of the measuring electrical currents are sequentially accomplished usually between all pairs of adjacent electrodes. This means that in a 16-electrode system the current is injected 16 times during each measuring cycle. During each current application, the resulting potential differences are measured between all 13 passive electrode pairs. This pattern of current injections and measurements of potential differences results in a set of 208 voltages acquired during each cycle. The voltage data obtained at the body surface are used to calculate the distribution of electrical impedance within the chest. This process is called image reconstruction as the calculated regional impedance values can be used to generate cross-sectional images, i.e., scans of their distribution in the chest. EIT scan rates are high, at present sampling rates of 40-50 scans/s are feasible. These scan rates are much higher than those that can be achieved with conventional radiological scanning by, e.g., CT or magnetic resonance tomography.

The most frequently used image reconstruction algorithms are based on difference imaging, i.e. they generate images of changes in regional electrical impedance. The image quality of this type of scans is better than of those showing absolute values of electrical impedance which are much more difficult to generate $[9,10]$. The regional changes in impedance are often normalised, i.e., they are calculated in relation to a regional reference impedance distribution. All EIT images shown in this review have been generated in this way, i.e., they are based on the calculation of relative impedance changes.

It is important to realise that the two-dimensional EIT scans represent the distribution of electrical impedance in a much larger slice of the chest than other established 
radiological scanning methods like CT. Tissues lying as much as $8 \mathrm{~cm}$ above or below the electrode plane still contribute to the imaged data $[11,12]$. This is caused by the fact that the measuring currents are much less confined to the studied chest plane than, e.g., X-rays.

Several review articles on EIT have been published in recent years where the interested readers may find further detailed information regarding this technology [10, 13-20].

\section{FUNCTIONAL EIT IMAGING}

The high scan rates achievable during EIT examinations and the acquisition of time series of EIT scans are the prerequisite for functional lung imaging. Functional imaging uses the local (i.e. pixel) time courses of the EIT signal to calculate one or more quantitative parameters characterizing the regional lung function. These newly derived indices are calculated from the EIT data in all image pixels and can then be plotted in the same pixel locations giving rise to new functional EIT scans. For instance, the cyclic variation of the EIT signal which typically occurs when EIT data are acquired on the chest during ventilation can be used to determine the magnitude of regional ventilation. This approach was one of the first methods of functional EIT data evaluation ever used [21, 22]. Fig. (2) shows a functional EIT scan of regional tidal volumes which was determined in an artificially ventilated pig by calculating the local average tidal amplitudes of the EIT signal between consecutive inspiratory maxima and expiratory minima. A CT scan acquired in the same chest plane is shown for comparison.
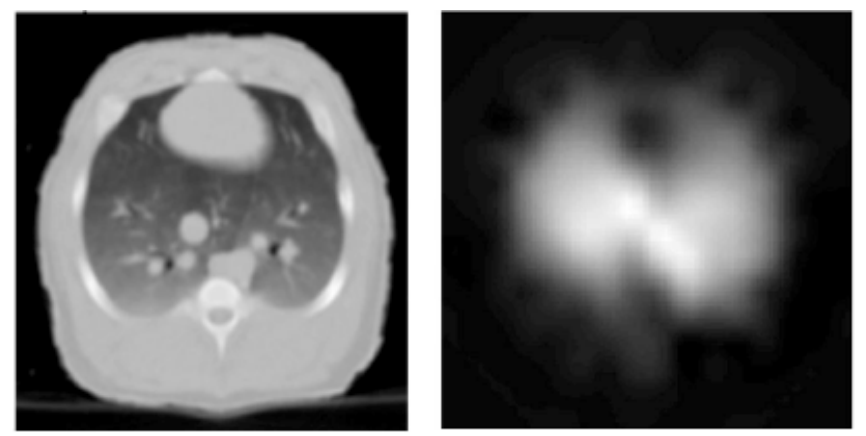

Fig. (2). A CT scan of a supine, mechanically ventilated pig showing the anatomical structures in the studied chest cross-section with the corresponding EIT scan showing the distribution of regional tidal volume.

Using the described approach of quantifying the ventilation-related changes in electrical impedance, functional EIT imaging is capable of characterising the distribution of ventilation in the chest cross-section under a variety of conditions (spontaneous breathing, artificial ventilation, healthy lungs or lung pathology) [19, 23-31] (see also Fig. 3, the upper scans). Other function-oriented approaches in EIT data evaluation allow the assessment of additional aspects of regional lung function. For instance, an increase in regional lung aeration leads to an increase in average regional lung impedance. The corresponding regional differences in impedance may be imaged as a functional scan and reflect the change in regional lung volumes $[32,33]$. In a clinical setting, this may be observed when the ventilator settings are modified, e.g., when regional lung aeration changes as a result of PEEP adjustment [30, 34] (see also Fig. 3, the lower scan). Pathological changes in lung electrical impedance resulting, e.g., from acute lung injury or lung collapse can also be visualised using this approach $[25,35,36]$. Further types of functional EIT scans aiming at the visualisation of the dynamics of regional lung emptying and filling have also been published [28, 37, 38].

Functional approach to EIT data evaluation has also been applied to assess regional lung perfusion [39-41]. This approach utilises the fact that lung ventilation and cardiac action occur at disparate rates. Both of these physiological processes elicit cyclic changes in regional electrical impedance which therefore can be analysed using principal component analysis and frequency filtering. The evaluation of regional time series of EIT data using this approach has been shown to render plausible results $[39,41]$. However, the validation of EIT in its ability to determine regional lung perfusion has not been accomplished yet and it remains to be established how the true blood flow fluctuations and the changes in vessel diameter contribute to the cardiac-synchronous variation of the EIT signal.

\section{THE VALUE OF EIT IN MONITORING PATIENTS WITH ARDS}

EIT has already been used to study adult [37, 42-44] and paediatric ARDS patients [27] as well neonatal patients suffering from respiratory distress syndrome $[45,46]$. The number of studied patients was rather low and EIT data were usually acquired only during short time intervals. Thus, the experience of EIT use in these patients is relatively scarce. The results of these EIT studies indicate a different and more inhomogeneous pattern of ventilation and aeration distribution in injured than in healthy lungs. It has also been shown that the regional effects of suctioning, PEEP change, surfactant administration, lung recruitment are discernible by EIT in these patients.

We may assume that if EIT monitoring is employed in ARDS patients in the future it will be used to monitor 1) the pathophysiological changes in the lung function which occur in the course of the development, progression and/or resolution of acute lung injury and 2) the effects of employed therapeutic measures, first of all of mechanical ventilation.

\section{MONITORING OF REGIONAL LUNG PATHO- PHYSIOLOGY IN ARDS}

It has been shown in several experimental studies that the development of lung oedema and the accompanying changes in regional lung aeration and ventilation induced by acute lung injury can be detected by EIT. This has been manifested in different experimental models of acute lung injury induced by repeated bronchoalveolar lavage [24, 33, 35], administration of oleic acid $[36,47,48]$ and endotoxin [49, 50], acid aspiration [47] as well as smoke inhalation [31]. The accumulation of fluid in the interstitium and alveoli decreases the electrical conductivity of the lung tissue which is accompanied by a fall in electrical impedance. Atelectasis and reduced lung compliance result in a redistribution of lung ventilation towards non-dependent lung regions [31, 35]. This was a typical finding whenever a global lung injury was induced. If the lung injury was restricted only to one lung region and the ventilator settings were not modified then decreased aeration and ventilation of the affected region was observed with compensatory aeration and ventilation changes in the unaffected lung areas [36]. 


\section{Distribution of regional tidal volume:}
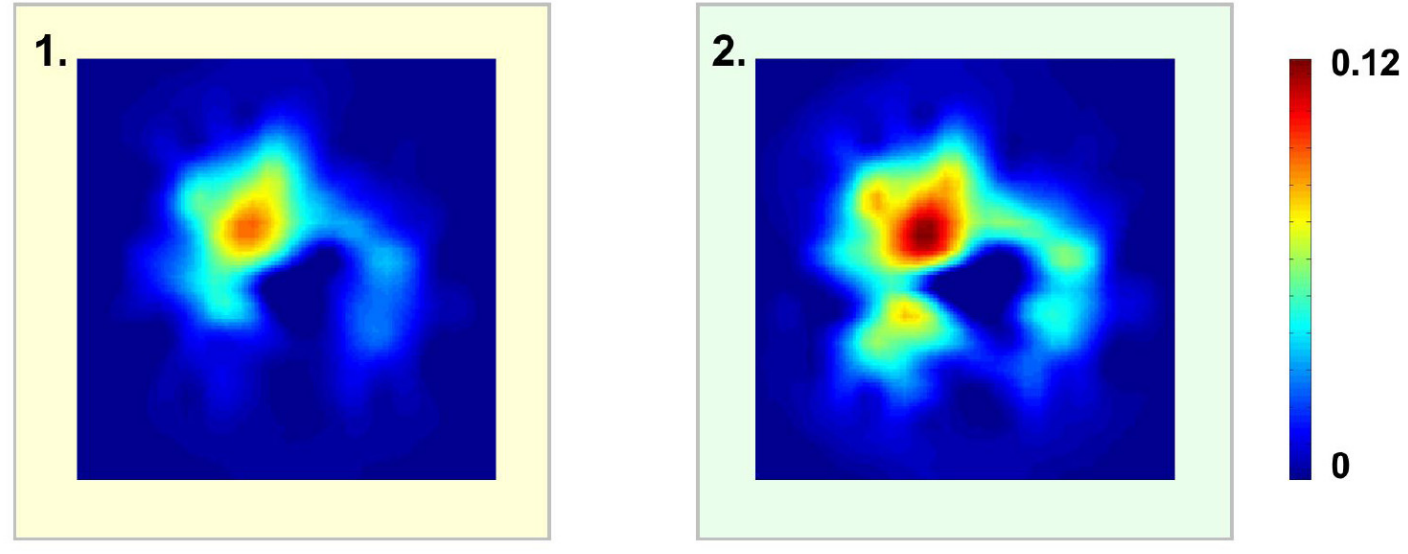

\section{Regional EIT signal:}
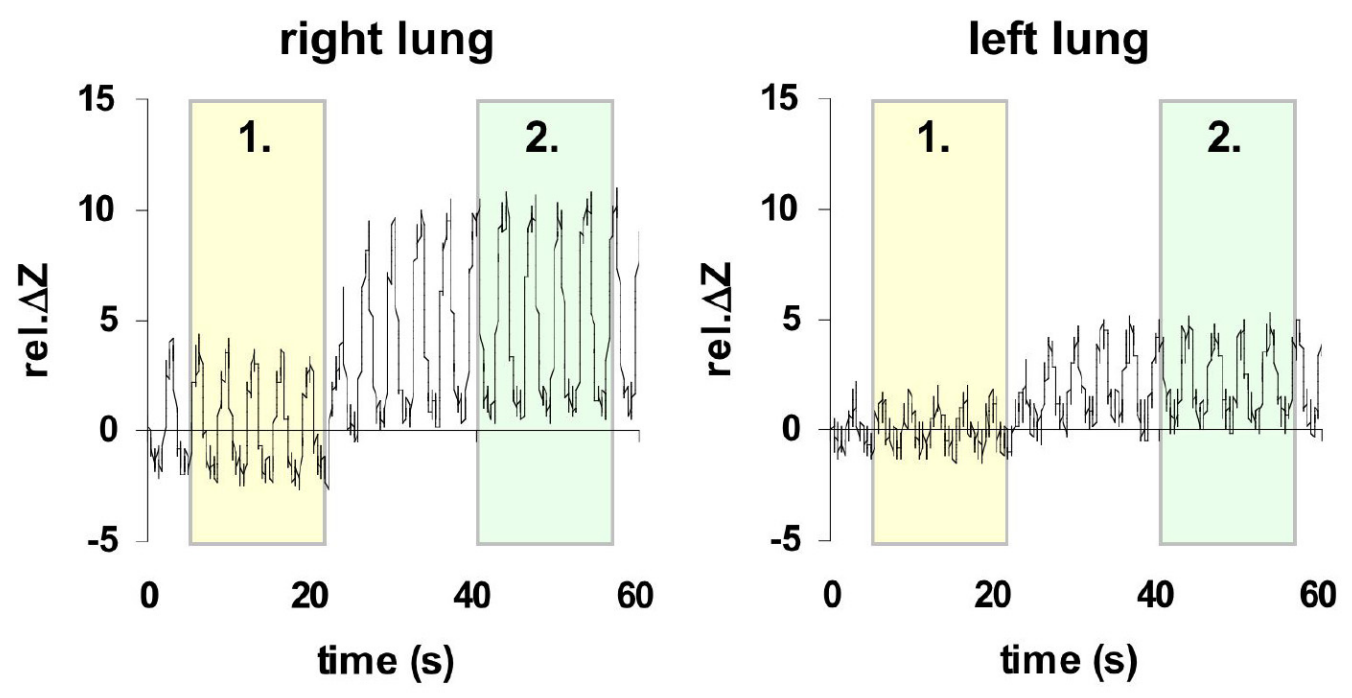

\section{Distribution of regional shift in lung volume:}

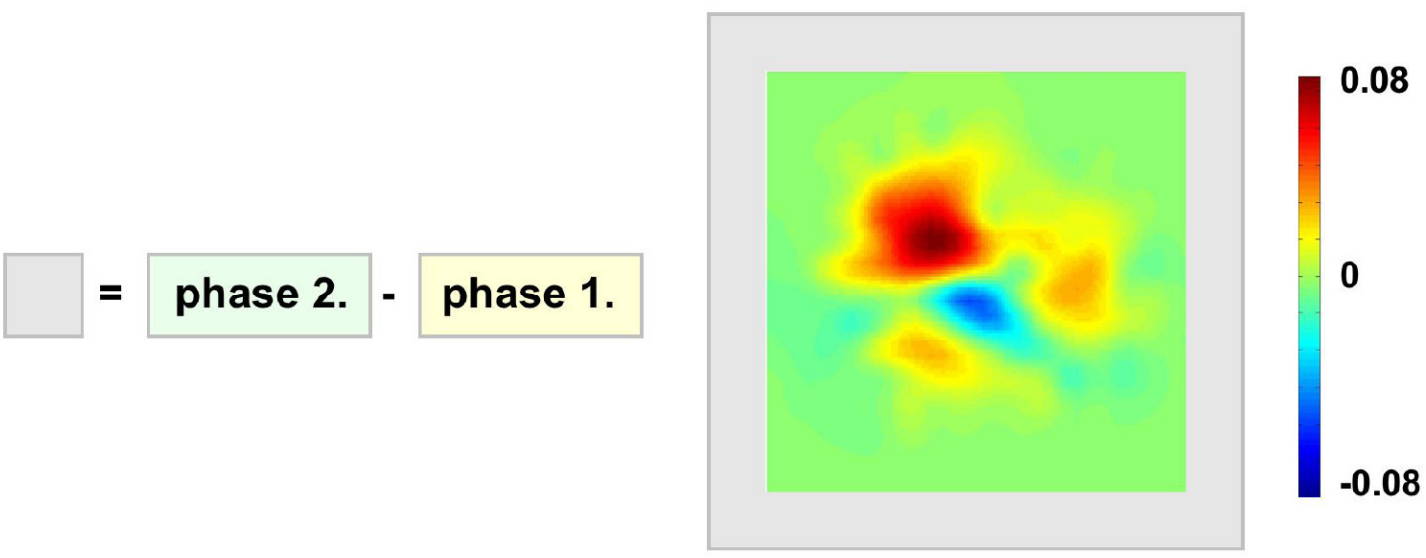

Fig. (3). EIT examination of a 70-year old supine mechanically ventilated patient with ARDS with pleural effusion in the left hemithorax. EIT data was acquired at $25 \mathrm{scans} / \mathrm{s}$. Initial ventilator settings during the first $20 \mathrm{~s}$ of the measurement were: tidal volume $9 \mathrm{ml} / \mathrm{kg}$ ideal body weight, positive end-expiratory pressure (PEEP) $0 \mathrm{~cm} \mathrm{H}_{2} \mathrm{O}$, breathing rate 17 breaths $/ \mathrm{min}$. Thereafter, PEEP was increased to $10 \mathrm{~cm} \mathrm{H}_{2} \mathrm{O}$. The functional EIT scans at the top show the distribution of regional tidal volume during the two highlighted phases of the measurement preceding and following the PEEP change. The functional EIT scan at the bottom shows the regional changes in mean lung volume induced by the PEEP increase with higher aeration occurring predominantly in the right non-dependent lung region. rel. $\Delta \mathrm{Z}$, relative impedance change. 
ARDS is known to affect the lung tissue heterogeneously leading to a pronounced ventilation/perfusion mismatch. The assessment of regional ventilation/perfusion matching by EIT and the generation of functional EIT scans showing the distribution of regional ventilation/perfusion ratios [16] is an intriguing possibility. However, although the ability of EIT to correctly quantify regional lung ventilation has been validated using other reference techniques $[43,47,48,51$ 53], this proof is still lacking in the case of regional lung perfusion. Several experimental and clinical studies have addressed the issue of lung perfusion imaging by EIT [40, 41, 54-57]. An adequate reference method was used in only one study [52], however, with only limited regional evaluation.

\section{MONITORING OF THERAPY EFFECTS ON REGIONAL LUNG FUNCTION IN ARDS}

The patients suffering from ARDS require mechanical ventilation which should not only guarantee sufficient gas exchange but should also be applied with the least injurious settings. It is recommended that low tidal volumes and adequate PEEP levels should be used in ARDS patients to minimise the possible incidence of alveolar overdistension as well as of tidal collapse and reopening of the alveoli.

EIT is able to assess regional tidal volumes and regional effects of PEEP adjustment. This is illustrated by an EIT examination of a patient with ARDS shown in Fig. (3). A 60-s time interval of this examination is shown during which PEEP was increased. The functional EIT scans in the upper part of the figure indicate how the magnitude and distribution of regional tidal volumes was influenced by the PEEP change. The functional EIT scan in the lower part of the figure shows the regional change in aeration induced by the increase in PEEP.

The regional ventilation and aeration distributions can be assessed by EIT consecutively during a sequence of multiple changes in ventilator settings, e.g. during an incremental and decremental PEEP trial $[24,25,58]$. The acquired data allow the identification of the ventilator settings with the most homogeneous ventilation distribution and with the least pronounced occurrence of lung overdistension. Such manoeuvres with parallel EIT examination can also be used to assess the lung volume recruitment.

It has also been shown that regional time courses of the EIT signal may characterise the nonlinearity of regional filling and emptying of lung regions [28] which in mechanically ventilated patients may be a sign of lung overdistension or collapse [37]. A downward curvilinearity of the regional EIT signal may result from lung overdistension whereas an upward curvilinearity may indicate recruitment. Another option to assess regional alveolar overdistension and recruitment is to perform a lowflow or stepwise inflation and deflation of the lungs, i.e., a pressure volume manoeuvre and to analyse the regional pressure-volume curves with EIT [44, 59, 60].

As EIT examinations can be performed with an excellent time resolution, dynamic changes in regional lung volumes can easily be assessed. The phase lag in regional lung filling and emptying can be detected [61] and delayed ventilation onset revealed [47]. The regional response of the lung tissue to a stepwise change in airway pressure can be studied by
EIT and regional respiratory time constants determined [42]. Fig. (4) shows an EIT examination in an adult ARDS patient clearly revealing the dissimilar time course of regional lung inflation in the non-dependent and dependent lung regions. Such manoeuvres can potentially be applied to assess the adequacy of chosen ventilator settings.

The use of lung protective ventilation is common in ARDS patients and the mentioned EIT studies have shown that various procedures in EIT data acquisition and evaluation with or without specific ventilatory manoeuvres may be used to derive regional EIT measures and generate information suitable for selecting the best ventilator settings. Several other therapeutic approaches have also been advocated in the management of ARDS patients which also may be monitored by EIT. These are recruitment manoeuvres, high frequency oscillation ventilation, surfactant administration, prone posture, restricted fluid administration, assisted ventilation allowing spontaneous breathing and partial liquid ventilation. Although the number of EIT studies addressing these approaches is not high, still almost all of these supportive and therapeutic procedures have already been followed by EIT, mostly in experimental $[33,35,62-64]$ and in few clinical studies [30, 45]. Fig. (5) illustrates the capacity of EIT to detect the effects of lung volume recruitment by an incremental PEEP increase to 30 $\mathrm{cm} \mathrm{H}_{2} \mathrm{O}$ and intratracheal administration of surfactant on regional lung ventilation distribution.

In general, it must be stated that the number of studies in which EIT was used to determine the effects of therapy on regional lung function is still rather low. Well designed clinical studies are needed to provide the evidence of the effectiveness of EIT use in patients.

\section{THE LIMITATIONS OF EIT}

Although this review has primarily described the potential benefits and the perspectives of EIT use in patients with ARDS it must be stated that, besides many positive features, this method also exhibits some limitations. One of these limitations is the relatively low image resolution of EIT. Although improvements in image quality can be expected with the development of advanced image reconstruction algorithms [65], the spatial resolution of EIT scans can not be decisively improved [66]. This has to be taken into account but should not be considered a major drawback. Excellent images of lung morphology can be acquired with established radiological imaging tools like CT or chest radiography and functional lung information can be additionally provided by EIT monitoring.

Another limitation is the necessity of measuring electrodes which have to be individually applied on the chest. The use of electrode belts may speed-up the application and render the care of patients easier but it remains to be established how the chest wall mechanics is affected by their use. At present, EIT scans are usually acquired in one electrode plane. This may limit the value of EIT monitoring as changes taking place in remote lung regions may be missed. This drawback may be reduced by performing measurements in multiple planes or by threedimensional imaging which, however, is not available at present due to the high complexity of the image reconstruction problem [67]. A certain solution might be the 

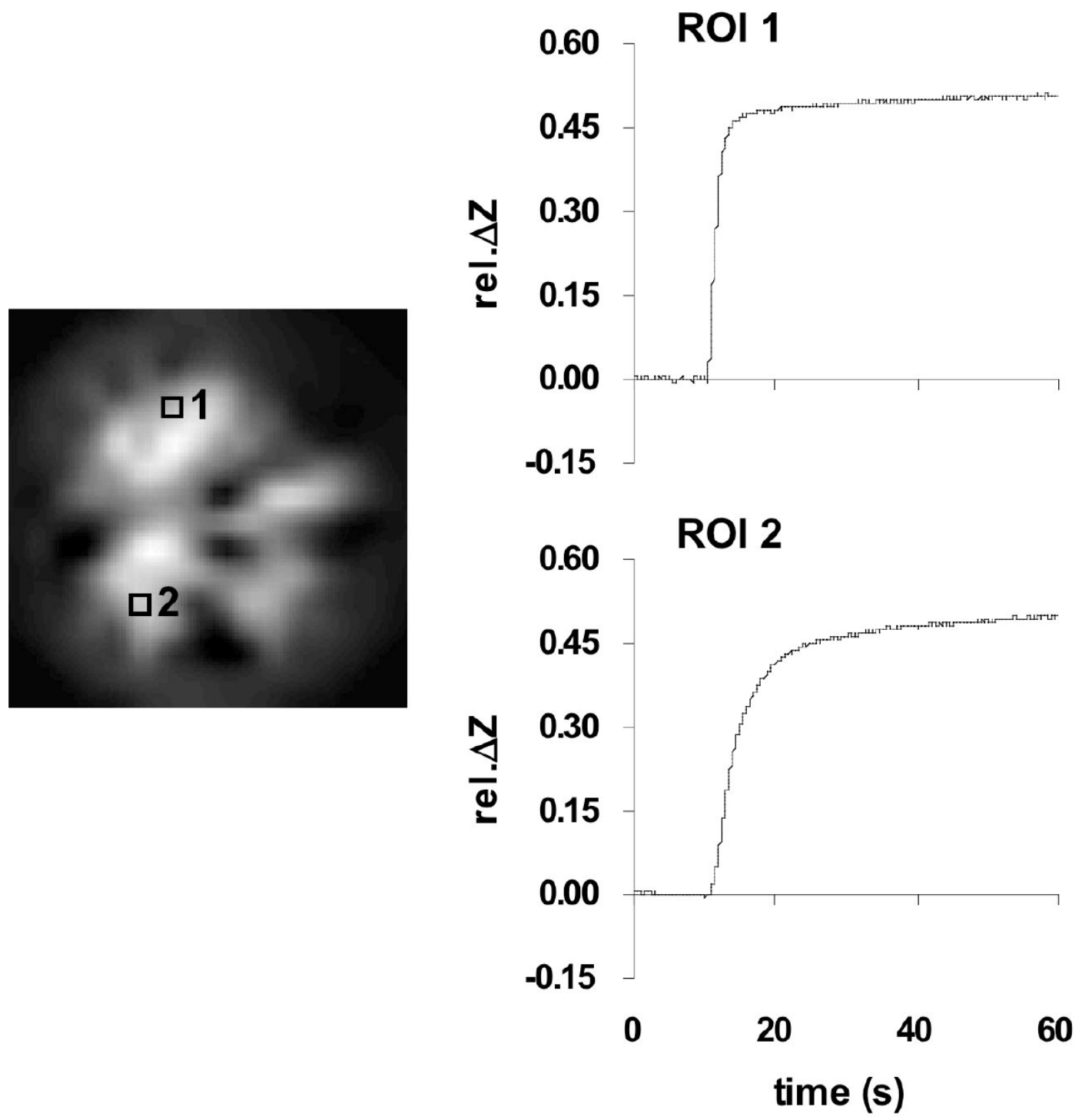

Fig. (4). EIT examination of a 55-year old supine mechanically ventilated patient with ARDS during a stepwise increase in airway pressure from 0 to $35 \mathrm{~cm} \mathrm{H} \mathrm{H}_{2} \mathrm{O}$. EIT data was acquired at $25 \mathrm{scans} / \mathrm{s}$. The functional EIT scan shows the increase in regional lung volume during the manoeuvre. The regional time courses of lung volume change in two regions of interest located in the anterior and posterior area of the right lung are shown. rel. $\Delta \mathrm{Z}$, relative impedance change.

above mentioned combination of established radiological imaging techniques with EIT: CT or chest radiography may provide the necessary anatomical information to adjust the location of the EIT electrode plane so that those lung regions, which might benefit most from functional monitoring, are assessed.

EIT has been used in only small and short-term clinical studies so far. Although EIT monitoring lasting for several hours or days has been described in case reports [46] no long-term clinical studies using EIT have ever been performed. The reproducibility of EIT findings has also been documented only over rather short time intervals [68]. Another aspect which has to be addressed is that although several EIT-based measures characterising regional lung function have been described in the past it has not been shown yet if any of these measures (or a combination of different EIT indices) can significantly affect the clinical decision-making process with a positive impact on the patients' outcome. This highlights the necessity of future prospective and multi-centre EIT studies.

\section{CONCLUSION}

EIT is a radiation-free imaging method which allows continuous assessment of regional lung function at the bedside. EIT has the potential of becoming a valuable tool for monitoring ARDS patients as it may generate information on regional lung ventilation, aeration as well as perfusion. Regional overdistension, collapse and recruitment can potentially be tracked by EIT and used to optimise the ventilator settings and minimise the incidence of ventilatorinduced lung injury. The value of EIT monitoring of ARDS patients still needs to be established in larger clinical trials. 
phase: NL
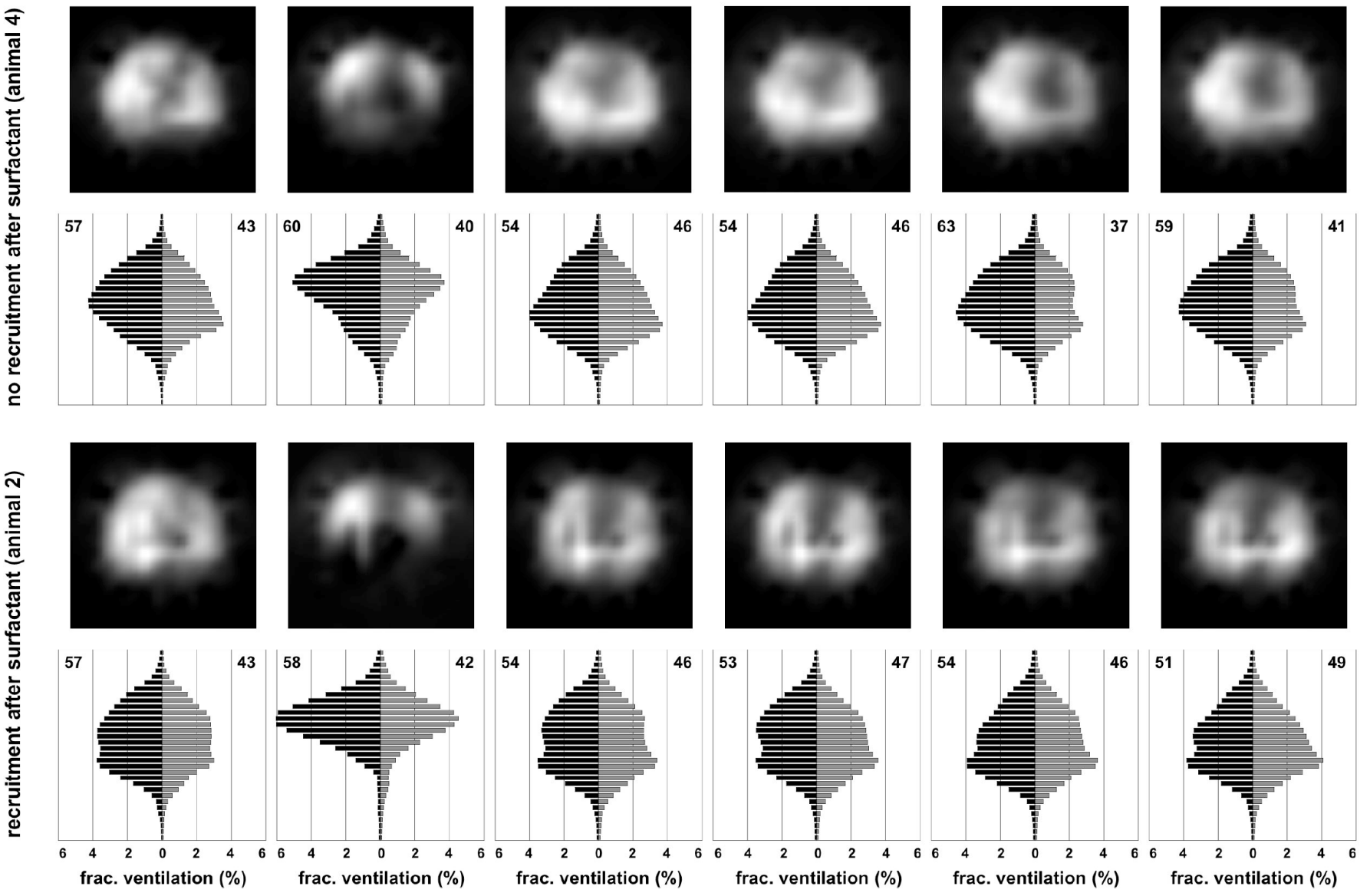

Fig. (5). Functional EIT scans of regional tidal volume distribution and fractional lung ventilation determined by EIT in two newborn piglets. The measurements were carried out before and after induction of acute lung injury and after endotracheal administration of surfactant. Six experimental phases are presented: NL normal lung, IL injured lung, IL-R injured lung after a recruitment manoeuvre, BS 1 min before surfactant administration, S-10 10 min after surfactant administration and S-60 60 min after surfactant administration. In animal 2 (bottom), an additional recruitment manoeuvre was performed immediately after surfactant administration. In animal 4 (top), no recruitment manoeuvre was performed. Anterior-to-posterior profiles of local ventilation, shown below the corresponding functional EIT scans, visualise the distribution of ventilation in the right and left halves of the chest (dark and light gray bars). The fractional ventilation in each ROI relative to the total ventilation in the whole chest cross-section is expressed as a percentage. The numbers in the left and right upper corners of these diagrams indicate the fractional ventilation in the right and left halves of the thoracic cross-section. Reprinted from [35] with permission of the American Thoracic Society.

\section{REFERENCES}

[1] Bernard GR, Artigas A, Brigham KL, et al. The AmericanEuropean Consensus Conference on ARDS. Definitions, mechanisms, relevant outcomes, and clinical trial coordination. Am J Respir Crit Care Med 1994; 149: 818-24.

[2] Phua J, Badia JR, Adhikari NK, et al. Has mortality from acute respiratory distress syndrome decreased over time?: A systematic review. Am J Respir Crit Care Med 2009; 179: 220-7.

[3] Rubenfeld GD, Herridge MS. Epidemiology and outcomes of acute lung injury. Chest 2007; 131: 554-62.

[4] Abel SJ, Finney SJ, Brett SJ, et al. Reduced mortality in association with the acute respiratory distress syndrome (ARDS). Thorax 1998; 53: 292-4.

[5] Zambon M, Vincent JL. Mortality rates for patients with acute lung injury/ARDS have decreased over time. Chest 2008; 133: 1120-7.

[6] Ventilation with lower tidal volumes as compared with traditional tidal volumes for acute lung injury and the acute respiratory distress syndrome. The Acute Respiratory Distress Syndrome Network. N Engl J Med 2000; 342: 1301-8.

[7] Geddes LA, Baker LE. The specific resistance of biological material-a compendium of data for the biomedical engineer and physiologist. Med Biol Eng 1967; 5: 271-93.
Faes TJ, van der Meij HA, de Munck JC, Heethaar RM. The electric resistivity of human tissues $(100 \mathrm{~Hz}-10 \mathrm{MHz})$ : a metaanalysis of review studies. Physiol Meas 1999; 20: R1-10.

[9] Barber DC. A review of image reconstruction techniques for electrical impedance tomography. Med Phys 1989; 16: 162-9.

[10] Lionheart WR. EIT reconstruction algorithms: pitfalls, challenges and recent developments. Physiol Meas 2004; 25: 125-42.

[11] Rabbani KS, Kabir AM. Studies on the effect of the third dimension on a two-dimensional electrical impedance tomography system. Clin Phys Physiol Meas 1991; 12: 393-402.

[12] Hahn G, Hartung C, Hellige G. Elektrische Impedanztomographie (EIT) als Methode zur regionalen Beurteilung der Lungenventilation. Mainz: Gustav Fischer Verlag; 1998.

[13] Bayford RH. Bioimpedance tomography (electrical impedance tomography). Ann Rev Biomed Eng 2006; 8: 63-91.

[14] Bodenstein M, David M, Markstaller K. Principles of electrical impedance tomography and its clinical application. Crit Care Med 2009; 37: 713-24.

[15] Brown BH. Electrical impedance tomography (EIT): a review. J Med Eng Technol 2003; 27: 97-108.

[16] Costa EL, Lima RG, Amato MB. Electrical impedance tomography. Curr Opin Crit Care 2009; 15: 18-24. 
[17] Frerichs I. Electrical impedance tomography (EIT) in applications related to lung and ventilation: a review of experimental and clinical activities. Physiol Meas 2000; 21: R1-21.

[18] Pillow JJ, Frerichs I, Stocks J. Lung function tests in neonates and infants with chronic lung disease: global and regional ventilation inhomogeneity. Pediatr Pulmonol 2006; 41: 105-21.

[19] Putensen C, Wrigge H, Zinserling J. Electrical impedance tomography guided ventilation therapy. Curr Opin Crit Care 2007; 13: 344-50.

[20] Boone K, Barber D, Brown B. Imaging with electricity: report of the European Concerted Action on Impedance Tomography. J Med Eng Technol 1997; 21: 201-32.

[21] Hahn G, Sipinkova I, Baisch F, Hellige G. Changes in the thoracic impedance distribution under different ventilatory conditions. Physiol Meas 1995; 16: A161-73.

[22] Leathard AD, Brown BH, Campbell J, et al. A comparison of ventilatory and cardiac related changes in EIT images of normal human lungs and of lungs with pulmonary emboli. Physiol Meas 1994; 15: A137-46.

[23] Meier T, Leibecke T, Eckmann C, et al. Electrical impedance tomography: changes in distribution of pulmonary ventilation during laparoscopic surgery in a porcine model. Langenbecks Arch Surg 2006; 391: 383-9.

[24] Meier T, Luepschen H, Karsten J, et al. Assessment of regional lung recruitment and derecruitment during a PEEP trial based on electrical impedance tomography. Intensive Care Med 2008; 34 : 543-50.

[25] Frerichs I, Dargaville PA, Dudykevych T, Rimensberger PC. Electrical impedance tomography: a method for monitoring regional lung aeration and tidal volume distribution? Intensive Care Med 2003; 29: 2312-6.

[26] Costa EL, Chaves CN, Gomes S, et al. Real-time detection of pneumothorax using electrical impedance tomography. Crit Care Med 2008; 36: 1230-8.

[27] Wolf GK, Grychtol B, Frerichs I, et al. Regional lung volume changes in children with acute respiratory distress syndrome during a derecruitment maneuver. Crit Care Med 2007; 35: 1972-8.

[28] Frerichs I, Dudykevych T, Hinz J, et al. Gravity effects on regional lung ventilation determined by functional EIT during parabolic flights. J Appl Physiol 2001; 91: 39-50.

[29] Hinz J, Moerer O, Neumann P, et al. Effect of positive endexpiratory-pressure on regional ventilation in patients with acute lung injury evaluated by electrical impedance tomography. Eur J Anaesthesiol 2005; 22: 817-25.

[30] Frerichs I, Hahn G, Golisch W, et al. Monitoring perioperative changes in distribution of pulmonary ventilation by functional electrical impedance tomography. Acta Anaesthesiol Scand 1998; 42: 721-6.

[31] Riedel T, Fraser JF, Dunster K, Fitzgibbon J, Schibler A. Effect of smoke inhalation on viscoelastic properties and ventilation distribution in sheep. J Appl Physiol 2006; 101: 763-70.

[32] Adler A, Shinozuka N, Berthiaume Y, Guardo R, Bates JH. Electrical impedance tomography can monitor dynamic hyperinflation in dogs. J Appl Physiol 1998; 84: 726-32.

[33] Odenstedt H, Lindgren S, Olegard C, et al. Slow moderate pressure recruitment maneuver minimizes negative circulatory and lung mechanic side effects: evaluation of recruitment maneuvers using electric impedance tomography. Intensive Care Med 2005; 31: 1706-14.

[34] Frerichs I, Hahn G, Hellige G. Thoracic electrical impedance tomographic measurements during volume controlled ventilationeffects of tidal volume and positive end-expiratory pressure. IEEE Trans Med Imaging 1999; 18: 764-73.

[35] Frerichs I, Dargaville PA, van Genderingen H, Morel DR, Rimensberger PC. Lung volume recruitment after surfactant administration modifies spatial distribution of ventilation. Am J Respir Crit Care Med 2006; 174: 772-9.

[36] Frerichs I, Hahn G, Schroder T, Hellige G. Electrical impedance tomography in monitoring experimental lung injury. Intensive Care Med 1998; $24:$ 829-36.

[37] Hinz J, Gehoff A, Moerer O, et al. Regional filling characteristics of the lungs in mechanically ventilated patients with acute lung injury. Eur J Anaesthesiol 2007; 24: 414-24.

[38] Pulletz S, Elke G, Zick G, et al. Performance of electrical impedance tomography in detecting regional tidal volumes during one-lung ventilation. Acta Anaesthesiol Scand 2008; 52: 1131-9.
[39] Deibele JM, Luepschen H, Leonhardt S. Dynamic separation of pulmonary and cardiac changes in electrical impedance tomography. Physiol Meas 2008; 29: S1-14.

[40] Dunlop S, Hough J, Riedel T, et al. Electrical impedance tomography in extremely prematurely born infants and during high frequency oscillatory ventilation analyzed in the frequency domain. Physiol Meas 2006; 27: 1151-65.

[41] Frerichs I, Pulletz S, Elke G, et al. Assessment of changes in distribution of lung perfusion by electrical impedance tomography. Respiration 2009; 77: 282-91.

[42] Pulletz S, Kott M, Elke G, et al. Optimization of artificial ventilation by regional respiratory time constants in patients with acute lung injury. Am J Respir Crit Care Med 2009; 179: A3844.

[43] Victorino JA, Borges JB, Okamoto $\mathrm{VN}$, et al. Imbalances in regional lung ventilation: a validation study on electrical impedance tomography. Am J Respir Crit Care Med 2004; 169: 791-800

[44] Hinz J, Moerer O, Neumann P, et al. Regional pulmonary pressure volume curves in mechanically ventilated patients with acute respiratory failure measured by electrical impedance tomography. Acta Anaesthesiol Scand 2006; 50: 331-9.

[45] van Veenendaal MB, Miedema M, de Jongh FH, et al. Effect of closed endotracheal suction in high-frequency ventilated premature infants measured with electrical impedance tomography. Intensive Care Med 2009; 35: 2130-4.

[46] Frerichs I, Schiffmann H, Hahn G, Hellige G. Non-invasive radiation-free monitoring of regional lung ventilation in critically ill infants. Intensive Care Med 2001; 27: 1385-94.

[47] Wrigge H, Zinserling J, Muders T, et al. Electrical impedance tomography compared with thoracic computed tomography during a slow inflation maneuver in experimental models of lung injury. Crit Care Med 2008; 36: 903-9.

[48] Hinz J, Neumann P, Dudykevych T, et al. Regional ventilation by electrical impedance tomography: a comparison with ventilation scintigraphy in pigs. Chest 2003; 124: 314-22.

[49] Fagerberg A, Sondergaard S, Karason S, Aneman A. Electrical impedence tomography and heterogeneity of pulmonary perfusion and ventilation in porcine acute lung injury. Acta Anaesthesiol Scand 2009; 53: 1300-9.

[50] Herber-Jonat S, Hajek K, Mittal R, et al. Electrical impedance tomography is able to track changes in respiratory function in endotoxin-challenged rodents. Respirology 2009; 14: 680-8.

[51] Frerichs I, Hinz J, Herrmann P, et al. Detection of local lung air content by electrical impedance tomography compared with electron beam CT. J Appl Physiol 2002; 93: 660-6.

[52] Kunst PW, Vonk Noordegraaf A, Hoekstra OS, Postmus PE, de Vries PM. Ventilation and perfusion imaging by electrical impedance tomography: a comparison with radionuclide scanning. Physiol Meas 1998; 19: 481-90.

[53] Richard JC, Pouzot C, Gros A, et al. Electrical impedance tomography compared to positron emission tomography for the measurement of regional lung ventilation: an experimental study. Crit Care 2009; 13: R82.

[54] Fagerberg A, Stenqvist O, Aneman A. Monitoring pulmonary perfusion by electrical impedance tomography: an evaluation in a pig model. Acta Anaesthesiol Scand 2009; 53: 152-8.

[55] Smit HJ, Vonk Noordegraaf A, Marcus JT, et al. Determinants of pulmonary perfusion measured by electrical impedance tomography. Eur J Appl Physiol 2004; 92: 45-9.

[56] Smit HJ, Vonk Noordegraaf A, Roeleveld RJ, et al. Epoprostenolinduced pulmonary vasodilatation in patients with pulmonary hypertension measured by electrical impedance tomography. Physiol Meas 2002; 23: 237-43.

[57] Vonk Noordegraaf A, Kunst PW, Janse A, et al. Pulmonary perfusion measured by means of electrical impedance tomography. Physiol Meas 1998; 19: 263-73.

[58] Costa EL, Borges JB, Melo A, et al. Bedside estimation of recruitable alveolar collapse and hyperdistension by electrical impedance tomography. Intensive Care Med 2009; 35: 1132-7.

[59] Kunst PW, Bohm SH, Vazquez de Anda G, et al. Regional pressure volume curves by electrical impedance tomography in a model of acute lung injury. Crit Care Med 2000; 28: 178-83.

[60] van Genderingen HR, van Vught AJ, Jansen JR. Estimation of regional lung volume changes by electrical impedance pressures tomography during a pressure-volume maneuver. Intensive Care Med 2003; 29: 233-40. 
[61] Riedel T, Kyburz M, Latzin P, Thamrin C, Frey U. Regional and overall ventilation inhomogeneities in preterm and term-born infants. Intensive Care Med 2009; 35: 144-51.

[62] Wolf GK, Grychtol B, Walsh BK, Zurakowski D, Arnold JH. Regional lung opening and closing characteristics during high frequency oscillatory ventilation. Am J Respir Crit Care Med 2009; 179: A4630.

[63] van Genderingen HR, van Vught AJ, Jansen JR. Regional lung volume during high-frequency oscillatory ventilation by electrical impedance tomography. Crit Care Med 2004; 32: 787-94.

[64] Lindgren S, Odenstedt $\mathrm{H}$, Olegard $\mathrm{C}$, et al. Regional lung derecruitment after endotracheal suction during volume- or pressure-controlled ventilation: a study using electric impedance tomography. Intensive Care Med 2007; 33: 172-80.
[65] Adler A, Arnold JH, Bayford R, et al. GREIT: a unified approach to 2D linear EIT reconstruction of lung images. Physiol Meas 2009; 30: S35-55.

[66] Seagar AD, Barber DC, Brown BH. Theoretical limits to sensitivity and resolution in impedance imaging. Clin Phys Physiol Meas 1987; 8 Suppl A: 13-31.

[67] Metherall P, Barber DC, Smallwood RH, Brown BH. Threedimensional electrical impedance tomography. Nature 1996; 380: 509-12.

[68] Frerichs I, Schmitz G, Pulletz S, et al. Reproducibility of regional lung ventilation distribution determined by electrical impedance tomography during mechanical ventilation. Physiol Meas 2007; 28: S261-7.

(C) Frerichs et al.; Licensee Bentham Open.

This is an open access article licensed under the terms of the Creative Commons Attribution Non-Commercial License (http: //creativecommons.org/licenses/by-nc/ 3.0/) which permits unrestricted, non-commercial use, distribution and reproduction in any medium, provided the work is properly cited. 